\title{
Menu Costs and the Long-Run Output-Inflation Trade-off
}

\author{
Michael B. Devereux \\ University of British Columbia \\ James Yetman* \\ University of Hong Kong
}

October 10, 2001

\begin{abstract}
In standard, New Keynesian models, there exists an unlimited long-run trade-off between output and inflation. But when we allow for an endogenous frequency of price adjustment, this is replaced by an inverted U-shaped relationship.
\end{abstract}

Keywords: Menu Costs, Phillips Curve JEL code: E31

* Corresponding Author: James Yetman, School of Economics and Finance, University of Hong Kong, Pokfulam Road, Hong Kong, jyetman@econ.hku.hk, phone (852) 2857-8506, fax (852) 2548-1152. This paper benefitted from the comments of an anonymous referee. Any remaining errors are the authors' responsibility. 


\section{Introduction}

It has been noted (see Walsh 1998) that modern sticky-price New Keynesian models of the type originally developed by Calvo (1983) or Taylor (1979) do not satisfy the natural rate hypothesis, under which the unconditional mean of output is independent of monetary policy. In fact, in the Calvo model, there is a positively sloped long-run Phillips curve, so that there exists an unlimited long-run trade-off between inflation and output, no matter how large the inflation rate becomes. This is an undesirable feature of these models, since price setters are unlikely to continue following simple menu cost rules in the presence of high rates of inflation.

When we allow for an endogenous frequency of price adjustment as in Romer (1990), this feature of the standard price-setting model is eliminated. Price adjustment frequency rises sharply with higher rates of inflation, reducing the real effects of inflation on output. ${ }^{1}$ While there is a small positive trade-off at very low rates of inflation, this is eliminated very quickly as inflation rises. We find that when inflation exceeds an annual rate of two percent, there is a negative rather than a positive effect of long-run inflation on output. Then, when inflation rises above 40 percent annually, price adjustment frequency is so great that all effects of inflation on steady state output are eliminated, and the natural rate hypothesis is restored. Thus endogenous frequency of price adjustment with rational price setting results in a long-run Phillips curve that is qualitatively similar to Akerlof, Dickens and

\footnotetext{
1 Kiley (2000) has also pointed out that price stickiness tends to fall with higher inflation rates in menu cost models.
} 
Perry's (2000) model of near-rational wage and price setting. ${ }^{2}$

\section{A simple model of sticky prices}

The quantity theory equation (or the aggregate demand equation) is written in $\log$ terms as

$$
y_{t}=m_{t}-p_{t}
$$

where $y_{t}$ is aggregate output and $m_{t}-p_{t}$ represents real balances. Price adjustment occurs according to the probabilistic model of Calvo (1983), so firms set prices in advance based on desired prices, which reflect the nominal marginal cost facing the firm. This is assumed to equal the money supply,

$$
p_{t}^{*}=m_{t}
$$

which follows a random walk with drift,

$$
m_{t}-m_{t-1}=\mu+u_{t}
$$

Now consider the pricing decision of a representative firm. Let each firm face a constant discount factor, $\beta<1$. Then a firm that must set its price in advance experiences a loss in expected profits, relative to a situation where price adjustment is instantaneous. Following Walsh (1998), it may be shown that the loss in profits is approximately given by the squared deviation of the log price from the desired

2 Akerlof et al define near-rationality as the under weighting of the importance of inflation by firms and workers. Because the cost of near-rationality is increasing in the level of inflation, price setting will be increasingly rational as inflation rises. 
$\log$ price. Thus, any firm $i$ faces an expected loss of

$$
L_{t}=F+E_{t-1} \sum_{j=0}^{\infty}(\beta \kappa)^{j} \Theta\left(p_{t}(i)-p_{t+j}^{*}\right)^{2}+\frac{(1-\kappa)}{\kappa} \sum_{j=1}^{\infty}(\beta \kappa)^{j} L_{t+j}
$$

where $F$ is a menu cost that a firm must pay to adjust its price, and $p_{t}(i)$ is the price set by firm $i$ in period $t$, which is set using information up until period $t-1$, reflecting a one period lag in the publication of the money supply. It is straight forward to show that

$$
\begin{aligned}
p_{t}(i) & =(1-\beta \kappa) E_{t-1} \sum_{j=0}^{\infty}(\beta \kappa)^{j} p_{t+j}^{*} \\
& =m_{t-1}+\frac{1}{1-\beta \kappa} \mu .
\end{aligned}
$$

The aggregate price level will be given by

$$
\begin{aligned}
p_{t} & =(1-\kappa) p_{t}(i)+\kappa p_{t-1} \\
& =(1-\kappa) m_{t-1}+\kappa p_{t-1}+\frac{1-\kappa}{1-\beta \kappa} \mu,
\end{aligned}
$$

steady state output by

$$
\bar{y}=\frac{\kappa(1-\beta)}{(1-\beta \kappa)(1-\kappa)} \mu,
$$

and inflation variability by

$$
V(\pi)=V\left(p_{t}-p_{t-1}\right)=\frac{1-\kappa}{1+\kappa} \sigma_{u}^{2}
$$

With exogenous frequency of price adjustment $(\kappa)$, steady state output is increasing in the trend money growth rate, so that there is a long-run trade off between the two, while inflation variability is independent of trend money growth. 


\section{Endogenous frequency of price adjustment}

Assuming an exogenous probability of price adjustment $(1-\kappa)$ is clearly inconsistent with profit maximizing behavior on the part of firms. Relaxing this assumption, optimal $\kappa$ will minimize

$$
L=(1-\beta \kappa)\left(\frac{F}{\Theta}+\mu^{2} \frac{\beta \kappa}{(1-\beta \kappa)^{3}}+\sigma_{u}^{2} \frac{1}{(1-\beta \kappa)^{2}}\right) .
$$

Using comparative statics, we know that $\partial L / \partial \kappa=0$ and $\partial^{2} L / \partial \kappa^{2}>0$, and the reader can easily verify that

$$
\frac{d \kappa}{d \mu}=-\frac{\frac{\partial^{2} L}{\partial \kappa \partial \mu}}{\frac{\partial^{2} L}{\partial \kappa^{2}}}<0 .
$$

Profit maximizing firms respond to higher trend inflation by increasing the average frequency with which they set prices. As a result, inflation volatility is increasing in trend inflation, since price shocks are transmitted more rapidly when a higher portion of firms update their prices each period.

\section{Quantitative analysis}

To illustrate these results, we calibrate the above model for $\beta=0.985$ and $F / \Theta$ consistent with $\kappa=0.75$ when $\mu=0.01$ and $\sigma_{u}=0.01$. That is, if we view this as a quarterly model, menu costs are such that if annual inflation is $4 \%$ and quarterly inflation shocks have a standard deviation of $1 \%$, firms change their prices once a year on average.

From equation (7), we can see there are two effects of trend inflation on steady state output. The first, direct effect is positive, and arises as a feature of the standard price setting model, as noted above. The second, indirect effect, is negative, 
and comes about through the endogenous frequency of price adjustment. Figure 1 illustrates the relationship between trend inflation and steady state output, including both effects. Note that there is a positive trade-off when inflation is very low, and an annual inflation rate of 2 percent leads an annual output level that is 0.8 percent higher than when trend inflation is zero. But for annual inflation rates above 2 percent, the effect of endogenous contract adjustment is so great that the relationship between trend inflation and steady state output is negative. When annual inflation exceeds 40 percent, all firms update their prices every period $(\kappa=0)$, so that inflation has no further impact on the frequency of price adjustment, and therefore steady state output.

The link between trend inflation and optimal probability of price change $(1-\kappa)$ is shown in Figure 2. Higher trend inflation leads to an increased average frequency of price changes. Finally, figure 3 illustrates the positive correlation between trend inflation and inflation volatility.

\section{Conclusions}

In standard, New Keynesian models, price setters follow simple menu-cost rules, so that there exists an unlimited long-run trade-off between output and inflation. When we allow for an endogenous frequency of price adjustment, this unlimited trade-off is replaced by a long-run Phillips curve that is qualitatively similar to that in Akerlof, Dickens and Perry (2000). With higher inflation, firms increase the frequency of price adjustment, reducing the real effects of inflation on output. 


\section{References}

Akerlof, George A., Williams T. Dickens, and George L. Perry, 2000, Near-Rational Wage and Price Setting and the Long-Run Phillips Curve, Brookings Papers on Economic Activity, 1:2000, 1-60.

Calvo, Guillermo A., 1983, Staggered Prices in a Utility Maximizing Framework, Journal of Monetary Economics, 12, 983-998.

Kiley, Michael T., 2000, Endogenous Price Stickiness and Business Cycle Persistence, Journal of Money Credit and Banking, 32, 28-53.

Romer, David, 1990, Staggered Price Setting with Endogenous Frequency of Adjustment, Economics Letters, 32, 205-210.

Taylor, John B., 1979, Staggered Wage Setting in a Macro Model, American Economic Review, 69, 108-113.

Walsh, Carl, 1998, Monetary Theory and Policy (MIT Press, Cambridge). 

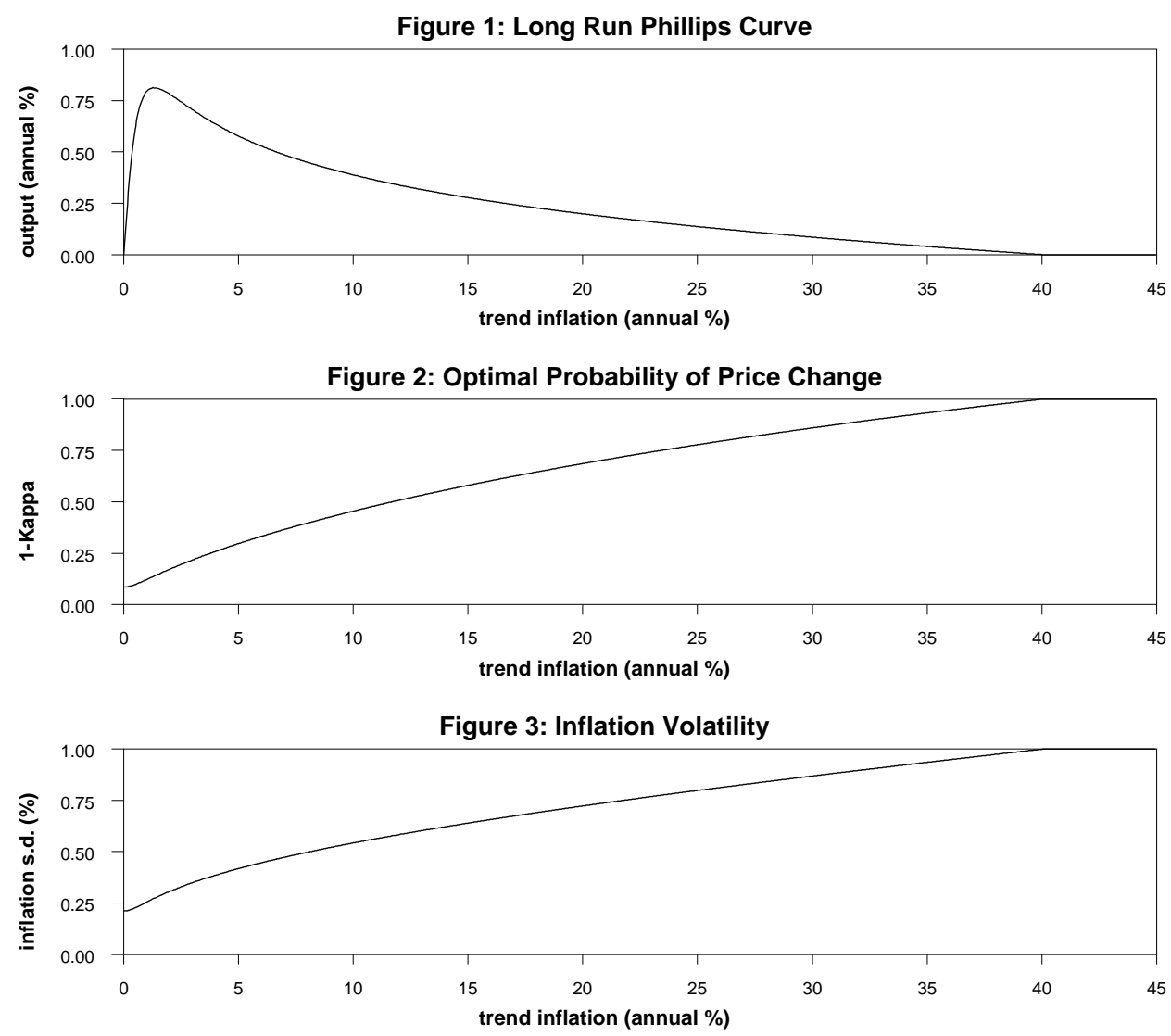